\title{
Assessment of early maladaptive schemas in patients with obsessive-compulsive disorder
}

\author{
Fatih Kizilagac $^{1}{ }^{(0)}$, Cem Cerit $^{1(0)}$ \\ ${ }^{1}$ Kocaeli University, Faculty of Medicine, Department of Psychiatry, Kocaeli - Turkey
}

\section{ABSTRACT}

Objective: Obsessive-Compulsive Disorder (OCD) is a chronic and severely disabling mental disorder with a fluctuating course that is characterized by persistent and unwanted thoughts and ritualistic behaviors. The aim of this study was to determine early maladaptive schemas in patients with obsessive compulsive disorder and to investigate related demographic and clinical factors.

Method: The study was carried out with 51 OCD patients and 51 healthy voluntary participants between June 01, 2017 and June 01, 2018 at the Psychiatry Department of Kocaeli University's Faculty of Medicine. Participants were assessed with Yale-Brown ObsessiveCompulsive Symptom Scale and Check List (Y-BOCS), Young Schema Questionnaire - Short Form 3 (YSQ-S3), Young-Rygh Avoidance Inventory (YRAI), Young Compensation Inventory, Beck Depression Inventory (BDI), and Hamilton Rating Scale for Anxiety (HAM-A).

Results: In OCD patients, enmeshment/undeveloped self, abandonment, failure, pessimism, vulnerability to harm or illness, emotional deprivation, social isolation/alienation, defectiveness/shame, approval seeking, insufficient self-control/self-discipline, self-sacrifice, and punitiveness schema scores were found significantly higher than in the control group. Psychosomatic symptoms and distraction-through-activity schema avoidance scores and status seeking, control and intolerance to criticism schema overcompensation scores in OCD patients were found significantly higher than in the control group. When depression and anxiety scores were adjusted in OCD patients; failure, insufficient self-control/self-discipline, self-sacrificing schemas and all schema domains were found to predict the severity of the disease. In addition, it was found that the vulnerability-to-harm-or-illness schema score and distraction-through-activity schema avoidance score predicted a decrease in the severity of disease.
\end{abstract}

Conclusion: The identification of schemas in OCD may be helpful in terms of the etiopathogenesis and treatment of the disease. In addition, studies on determination and reduction of schemas in OCD patients may be useful for an early treatment of the disease.

Keywords: Early maladaptive schemas, obsessive-compulsive disorder, schema avoidances, schema overcompensations.

\section{INTRODUCTION}

Obsessive-compulsive disorder (OCD) is a longlasting, persisting mental disease leading to a serious loss of functionality and a reduced quality of life. Its lifetime prevalence is around $2.5 \%$. Nevertheless, OCD patients tend to be late in seeking help, not until they have suffered serious problems due to their condition (1).
Schema therapy is an innovative and integrative therapy developed by Young et al. (2) expanding traditional cognitive-behavioral treatments and concepts significantly. Early maladaptive schemas are dysfunctional themes and patterns based on the person him- or herself and their relations with others, consisting of memories, emotions, cognition, and bodily sensations, originating early in life, developing during childhood and adolescence, and continuing

How to cite this article: Kizilagac F, Cerit C. Assessment of Early Maladaptive Schemas in Patients with Obsessive-Compulsive Disorder. Dusunen Adam The Journal of Psychiatry and Neurological Sciences 2019;32:14-22.

Correspondence: Fatih Kizilagac, Kocaeli University, Faculty of Medicine, Department of Psychiatry, Kocaeli, Turkey

Phone: +90-262-303-7575 E-mail: fatihkizil1987@hotmail.com

Received: November 09, 2018; Revised: November 16, 2018; Accepted: December 13, 2018 
throughout life. The schema model includes 18 early maladaptive schemas in five schema domains consisting of unmet basic emotional needs. It has been claimed that most early maladaptive schemas can cause depression, anxiety, substance addiction, and psychosomatic symptoms. While schema therapy was primarily developed for personality disorders, today it can be applied for a number of chronic mental illnesses. Treatment-resistant and recurrent depression and anxiety can benefit from schema therapy (2). Recent studies have shown positive effects of early maladaptive schema therapy in the treatment of OCD. In 2011, Haaland et al. (3) found that an improvement in the unsuccessful schema during confrontation and response prevention therapy in OCD patients was a predictor for the improvement of the patient's symptoms after treatment. Wilhelm et al. (4) found an (improved) treatment response in OCD patients to be significantly mediated by obsessive beliefs of perfectionism and certainty and maladaptive schemas of dependency and incompetence.

In other studies with early maladaptive schemas, Kim et al. (5) found that OCD patients scored significantly higher for the defectiveness/shame, social isolation/alienation, and failure schema dimensions than the control group. A study by Kwak et al. (6) comparing OCD patients, panic disorder patients, and a control group showed that in OCD patients, defectiveness/shame, social isolation/alienation, and failure schemas were prominently activated.

Studying schemas and reducing their intensity in OCD may be of advantage in the treatment of OCD patient and the reduction of the condition's severity. Aim of this study was to determine early maladaptive schemas in OCD patients and assess the demographic and clinical factors of the disease.

\section{METHOD}

The study was carried out with 51 volunteer subjects presenting to the outpatient clinic of the department for mental health and diseases of Kocaeli University's medical faculty who had received a diagnosis of OCD according to the diagnostic criteria of the DSM-5 (7). As a control group, 51 healthy individuals matching the patients according to educational status and sex were enrolled. Sociodemographic data for both groups are shown in Table 1 . In the patient group, 16 individuals (31.4\%) were male and $35(68.6 \%)$ female, while of the control group members, 23 (45.1\%) were male and 28 $(54.9 \%)$ female. Mean age in the patient group was
$26.62 \pm 9.92$ years and in the control group $27.15 \pm 7.35$ years. The mean duration of education was $13.03 \pm 3.19$ years in the patient group and $14.60 \pm 4.71$ years in the control group. Before beginning the study, we received approval from the ethics committee for non-invasive clinical research of Kocaeli University. Patients and healthy volunteer study participants were informed and gave written consent. Excluded from the study were persons below the age of 18 years, illiterates, persons with organic mental disorders and patients with mental comorbidities. The presence of mental comorbidities in OCD patients was first assessed by a psychiatrist.

\section{Measures}

Yale-Brown Obsessive-Compulsive Scale (Y-BOCS) Developed by Goodman et al. (8) in 1989, the Y-BOCS is a semi-structured measure administered by the interviewer to assess type and severity of obsessivecompulsive symptoms in patients diagnosed with OCD. A validity and reliability study for the Turkish form was carried out in 1993 by Karamustafaoglu et al. (9) and in 1995 by Tek et al. (10).

\section{Young Schema Questionnaire - Short Form Version 3 (YSQ-S3)}

An instrument developed by Young to assess people's early maladaptive schemas, consisting of 16 schemas and 205 items based on self-reporting (11). Participants are asked to score each item on a Likert-type scale from 1 to 6 according to the degree to which the item is relevant to describe them. Soygut et al. (12) carried out a validity and reliability study with university students for the YSQ-S3 in Turkey (12).

\section{Young-Rygh Avoidance Inventory (YRAI)}

In our study, we used the Young-Rygh Avoidance Inventory to assess avoidance behavior, which is one of the schema coping styles. The instrument was developed by Young and Rygh and contains a variety of coping mechanisms developed to deal with early maladaptive schemas (13). A validity and reliability study in Turkey was carried out in 2007 by Soygut et al. (12) in a university sample. The study showed the appropriateness of the instrument, which consists of six dimensions and 26 items (14).

\section{Young Compensation Inventory (YCI)}

For the measurement of schema-maintaining coping behaviors, we used the (YCI) developed by Young (15), which is based on self-reporting and consists of 48 
items. Psychometric studies regarding a form specific for Turkey have been made by Karaosmanoglu et al (16).

\section{Beck Depression Inventory (BDI)}

Developed by Beck et al. (17) to measure somatic, cognitive, emotional, and motivational symptoms seen in depression. The BDI was adapted for Turkish in 1988 and 1989 by Hisli $(18,19)$.

\section{Hamilton Rating Scale for Anxiety (HAM-A)}

A semi-structured instrument to be administered by the interviewer consisting of a five-point Likert-type scale, developed to measure the level and changing intensity of anxiety and to determine the symptom distribution (20). While Yazici et al. (21) carried out a validity and reliability study for Turkey in 1998, cutoff points for the Turkish forms were not calculated; the scale is only relevant in comparative studies.

\section{Data Analysis}

Statistical analyses were made using the SPSS 22 package. Normal distribution of the variables was assessed using Kolmogorov-Smirnov and Shapiro-Wilk tests. For the comparison of categorical data between groups, chi-square test was used. Numerical statistical data of groups not following normal distribution were compared using Mann-Whitney U-test. Numerical data for normally distributed groups was compared using independent-sample t-test. For correlations between numerical data, Pearson's and Spearman correlation analysis tests and direct regression analysis were used. The difference between groups was considered statistically significant when $\mathrm{p}<0.05$.

\section{RESULTS}

The study included 102 individuals, 51 patients and 51 healthy volunteers. Sociodemographic characteristics of patient and control groups and the patients' clinical characteristics are shown in Table 1. Between patient and control group, there was no significant difference regarding age, sex, duration of education, and other sociodemographic data. The mean onset age of the disease in the patients was $18.52 \pm 7.70$ years. The mean duration of disease in the patient group was $7.92 \pm 5.48$ years. The most frequently observed subdimension type

Table 1: Sociodemographic characteristics of $O C D$ patients and control group

\begin{tabular}{|c|c|c|c|c|c|c|c|}
\hline & \multicolumn{2}{|c|}{ Patient group } & \multicolumn{2}{|c|}{ Control group } & \multirow[b]{2}{*}{$\chi^{2}$} & \multirow[b]{2}{*}{$\mathbf{t}$} & \multirow[b]{2}{*}{$\mathbf{p}$} \\
\hline & Mean & SD & Mean & SD & & & \\
\hline Age & 26.62 & 9.92 & 27.15 & 7.35 & \multirow{6}{*}{1.495} & -0.306 & 0.760 \\
\hline Sex & $\mathbf{n}$ & $\%$ & $\mathbf{n}$ & $\%$ & & & \\
\hline Male & 16 & 31.4 & 23 & 45.1 & & & בכב 0 \\
\hline Female & 35 & 68.6 & 28 & 54.9 & & & 0.222 \\
\hline \multirow[t]{2}{*}{ Years of education } & Mean & SD & Mean & SD & & & \\
\hline & 13.03 & 3.19 & 14.60 & 4.71 & & -1.968 & 0.052 \\
\hline Marital status & $\mathbf{n}$ & $\%$ & $\mathbf{n}$ & $\%$ & \multirow{13}{*}{0.058} & & \\
\hline Married & 10 & 19.6 & 12 & 23.5 & & & \\
\hline \multirow[t]{2}{*}{ Unmarried } & 41 & 80.4 & 39 & 76.5 & & & 0.810 \\
\hline & Mean & SD & & & & & \\
\hline Age at onset & 18.52 & 7.70 & & & & & \\
\hline Duration of disease (years) & 7.92 & 5.48 & & & & & \\
\hline Number of hospitalizations & 0.58 & 0.23 & & & & & \\
\hline OCD symptom dimensions & $\mathbf{n}$ & $\%$ & & & & & \\
\hline Contamination and cleaning & 40 & 78.4 & & & & & \\
\hline Aggression-control & 36 & 70.6 & & & & & \\
\hline Arranging-symmetry & 22 & 43.1 & & & & & \\
\hline Religious-sexual & 22 & 43.1 & & & & & \\
\hline Hoarding & 7 & 13.7 & & & & & \\
\hline
\end{tabular}


in OCD patients was contamination and cleaning, followed by aggression-control, arranging-symmetry, and religious-sexual subdimension. The most rarely seen subdimension was hoarding.

The mean total Y-BOCS score for OCD patients was $20.35 \pm 6.86$, the mean total BDI score $18.86 \pm 10.79$, the mean total HAM-A score $12.52 \pm 6.12$. These instruments were not administered to the healthy control group.

Correlations between the scales used for the OCD patients are shown in Table 2, showing that Y-BOCS scores are positively correlated with BDI and HAM-A scores at a statistically significant level, BDI scores have a statistically significant positive correlation with Y-BOCS and HAM-A scores, and HAM-A scores are statistically significantly positively correlated with Y-BOCS and BDI scores.

A comparison of early maladaptive schemas between OCD patients and the control group is shown in Table 3 . OCD patients had higher scores than the controls in all schema domains (impaired autonomy, disconnection/ rejection, unrelenting standards, impaired limits, otherdirectedness) as well as in the schemas enmeshment/ undeveloped self, abandonment, failure, pessimism, vulnerability to harm or illness, social isolation/alienation, defectiveness/shame, approval seeking, punitiveness, emotional deprivation, insufficient self-control and/or self-discipline, and self-sacrifice. Furthermore, schema avoidance scores for psychosomatic symptoms and distraction through activity and schema overcompensation scores for status seeking, control, and intolerance to criticism were significantly higher in the patient group compared to the controls. Comparison of Young-Rygh Avoidance Inventory and Young Compensation Inventory scores between OCD patients and the control group is shown in Table 4.

Table 5 shows the degree to which early maladaptive schemas in OCD patients predict the severity of OCD. The schema domains impaired autonomy and disconnection/rejection, the pessimism and unrelenting standards schemas, psychosomatic schema avoidance, and status seeking and defiance schema overcompensations were found to predict OCD severity. An increase in the emotion control schema avoidance score and in the egocentrism overcompensation score predicted a decrease in the severity of OCD. Furthermore, Table 4 shows how far early maladaptive schemas and schema domains predict the severity of OCD after the adjustment of BDI and HAM-A scores: After adjustment of anxiety and depression scores, all schema domains (impaired autonomy, disconnection/rejection,
Table 2: Pairwise correlation of OCD patients' clinical scale scores

\begin{tabular}{lccc} 
& Y-BOCS r (p) & BDI r $(\mathbf{p})$ & HAM-A r (p) \\
\hline BDI & 0.591 & & 0.688 \\
& $(<0.001)$ & & $(<0.001)$ \\
HAM-A & 0.589 & 0.688 & \\
& $(<0.001)$ & $(<0.001)$ & \\
Y-BOCS & & 0.591 & 0.589 \\
& & $(<0.001)$ & $(<0.001)$ \\
\hline
\end{tabular}

r: Pearson correlation coefficient

OCD: Obsessive-Compulsive Disorder, BDI: Beck Depression Inventory, HAM-A Hamilton Rating Scale for Anxiety, Y-BOCS: Yale-Brown Obsessive-Compulsive Scale

unrelenting standards, impaired limits, and otherdirectedness) and the schemas pessimism, insufficient self-control and/or self-discipline and self-sacrifice predict the severity of OCD. An increase in the vulnerability-to-harm-or-illness schema score and in the distraction-through-activity schema avoidance score predicted a decrease in the severity of OCD.

\section{DISCUSSION}

Early maladaptive schemas generally develop during childhood and adolescence and tend to be resistant to change (2). While it is said that schemas may remain latent in certain patients and be triggered when the disease flares up, Delattre et al. (22) showed that in anxiety disorder almost all schema scores were elevated compared to the control group, which suggests that there are no schemas that are specific to anxiety disorder or mental illnesses. Atalay et al. (23) found significantly higher scores in comparison with the control group for the schemas isolation/alienation, vulnerability and pessimism, emotional deprivation, defectiveness/shame, failure, incompetence, subjugation, unrelenting standards, entitlement, and approval seeking. Our results support the outcomes of these studies. We found an increase in most schemas in our OCD patient group compared to the controls. These higher values were significant for the schemas enmeshment/undeveloped self, abandonment, failure, pessimism, vulnerability to harm or illness, social isolation/alienation, defectiveness/ shame, approval seeking, punitiveness, emotional deprivation, insufficient self-control and/or selfdiscipline, and self-sacrifice.

Individuals with a dependency schema may feel unable to look after themselves, solve their daily tasks, or to give adequate judgments and make good decisions (24). OCD patients' difficulties in decision-making may also result from their dependency schema, feeling the 
Table 3: Comparison of early maladaptive schema scores between OCD patients and control group

\begin{tabular}{|c|c|c|c|c|c|c|c|c|c|c|}
\hline & \multicolumn{4}{|c|}{ OCD Patients } & \multicolumn{4}{|c|}{ Control Group } & \multirow[b]{2}{*}{$\mathbf{t}$} & \multirow[b]{2}{*}{$\mathbf{p}$} \\
\hline & Mean & SD & Median & Min-Max & Mean & SD & Median & Min-Max & & \\
\hline \multicolumn{11}{|l|}{ YSQ-S3 } \\
\hline Impaired autonomy & 79.56 & 25.04 & & & 50.27 & 13.89 & & & 7.303 & $<0.001$ \\
\hline $\begin{array}{l}\text { Enmeshment/ } \\
\text { undeveloped self }\end{array}$ & 22.39 & 8.69 & & & 13.80 & 4.71 & & & 6.200 & $<0.001$ \\
\hline Abandonment & 12.56 & 5.34 & & & 7.39 & 2.16 & & & 6.407 & $<0.001$ \\
\hline Failure & 16.33 & 6.37 & & & 10.39 & 3.62 & & & 5.789 & $<0.001$ \\
\hline Pessimism & 16.05 & 6.51 & & & 9.72 & 4.08 & & & 5.881 & $<0.001$ \\
\hline $\begin{array}{l}\text { Vulnerability to } \\
\text { harm or illness }\end{array}$ & 13.09 & 5.11 & & & 9.23 & 3.69 & & & 4.373 & $<0.001$ \\
\hline $\begin{array}{l}\text { Disconnection/ } \\
\text { rejection }\end{array}$ & 58.37 & 20.62 & & & 43.33 & 13.42 & & & 4.364 & $<0.001$ \\
\hline $\begin{array}{l}\text { Emotional } \\
\text { deprivation }\end{array}$ & & & 10.00 & $5-26$ & & & 7.00 & $5-26$ & & 0.012 \\
\hline $\begin{array}{l}\text { Emotional } \\
\text { inhibition }\end{array}$ & 12.01 & 5.58 & & & 10.31 & 3.66 & & & 1.823 & 0.072 \\
\hline $\begin{array}{l}\text { Social isolation/ } \\
\text { alienation }\end{array}$ & 20.72 & 7.97 & & & 15.17 & 5.08 & & & 4.191 & $<0.001$ \\
\hline $\begin{array}{l}\text { Defectiveness/ } \\
\text { shame }\end{array}$ & & & 12.00 & $6-32$ & & & 9.00 & $6-21$ & & $<0.001$ \\
\hline $\begin{array}{l}\text { Unrelenting } \\
\text { standards }\end{array}$ & 31.74 & 8.45 & & & 25.35 & 5.88 & & & 4.433 & $<0.001$ \\
\hline $\begin{array}{l}\text { Unrelenting } \\
\text { standards }\end{array}$ & 9.35 & 4.39 & & & 8.05 & 3.11 & & & 1.717 & 0.089 \\
\hline Approval seeking & & & 23.00 & $7-32$ & & & 18.00 & $6-25$ & & $<0.001$ \\
\hline Impaired limits & & & 24.00 & $14-37$ & & & 20.00 & $9-40$ & & 0.003 \\
\hline $\begin{array}{l}\text { İnsufficient } \\
\text { self-control and/ } \\
\text { or self-discipline }\end{array}$ & & & 24.00 & $14-37$ & & & 20.00 & $9-40$ & & 0.003 \\
\hline Other-directedness & 40.50 & 9.41 & & & 32.78 & 8.76 & & & 4.289 & $<0.001$ \\
\hline Self-sacrifice & 16.90 & 5.67 & & & 13.52 & 4.42 & & & 3.346 & 0.001 \\
\hline Punitiveness & 23.41 & 5.89 & & & 19.27 & 5.68 & & & 3.609 & $<0.001$ \\
\hline
\end{tabular}

SD: Standard deviation, t: $t$ test value, med.: median value

OCD: Obsessive-Compulsive Disorder, YSQ-S3: Young Schema Questionnaire - Short Form 3

need for other people's confirmation. Individuals with a failure schema hold a belief that they will inevitably be unsuccessful or insufficient compared to their peers, in areas of success (such as school, career, or sports) (24). We may say that the impaired functionality of OCD patients due to the disorder, involving a significant loss of time in their work and school lives, could be related to this schema. People with a social isolation schema feel that they are different from others, not belonging to any group or community (24). OCD patients tend to hide their obsessions and compulsions. They may also withdraw from society due to their contamination obsession. Individuals with a punitiveness schema believe that they need to be severely punished for mistakes they make (24). OCD patients, because of their rigid adherence to rules, may tend to support exaggerated punishment for themselves and others in cases of mistakes. Individuals with an approval-seeking schema overemphasize other people's confirmation, acceptance, and interest rather than to create a safe and right sense of self (24). OCD patients may also feel a need for confirmation by others to counter their obsessions with doubt and insecurity. Individuals with pessimism schema downplay the positive sides of life and focus on the negative aspects (24). In our study, the increase in the depression scores in our patients may have been the reason for their focusing on negativity. Individuals with self-sacrifice schemas focus on other 
Table 4: Comparison of Young-Rygh Avoidance Inventory and Young Compensation Inventory scores between OCD patients and control group

\begin{tabular}{|c|c|c|c|c|c|c|c|c|c|c|}
\hline & \multicolumn{4}{|c|}{ OCD Patients } & \multicolumn{4}{|c|}{ Control Group } & \multirow[b]{2}{*}{$\mathbf{t}$} & \multirow[b]{2}{*}{$\mathbf{p}$} \\
\hline & Mean & SD & Median & Min-Max & Mean & SD & Median & Min-Max & & \\
\hline \multicolumn{11}{|l|}{ YRAI } \\
\hline $\begin{array}{l}\text { Psychosomatic } \\
\text { symptoms }\end{array}$ & 18.50 & 8.08 & & & 14.80 & 6.41 & & & 2.564 & 0.012 \\
\hline $\begin{array}{l}\text { Intentionally not } \\
\text { thinking about } \\
\text { upsetting things }\end{array}$ & 12.96 & 4.57 & & & 11.58 & 3.82 & & & 1.644 & 0.103 \\
\hline Emotion control & 15.92 & 4.04 & & & 14.60 & 4.03 & & & 1.642 & 0.104 \\
\hline Withdrawal from people & 12.25 & 3.82 & & & 10.84 & 3.60 & & & 1.919 & 0.058 \\
\hline $\begin{array}{l}\text { Distraction through } \\
\text { activity }\end{array}$ & 11.05 & 3.34 & & & 8.11 & 2.64 & & & 4.929 & $<0.001$ \\
\hline Suppression of emotions & 7.45 & 2.46 & & & 6.72 & 2.08 & & & 1.605 & 0.112 \\
\hline \multicolumn{11}{|l|}{ YCI } \\
\hline Status seeking & 24.01 & 9.92 & & & 19.43 & 5.79 & & & 2.852 & 0.006 \\
\hline Control & 25.31 & 6.38 & & & 21.39 & 6.29 & & & 3.121 & 0.002 \\
\hline Rebellion & 12.62 & 4.73 & & & 11.49 & 4.70 & & & 1.216 & 0.227 \\
\hline Counterdependency & 19.72 & 4.84 & & & 19.19 & 4.79 & & & 0.555 & 0.580 \\
\hline Manipulation & 14.64 & 5.32 & & & 12.80 & 4.05 & & & 1.965 & 0.052 \\
\hline Intolerance to criticism & & & 9.00 & $4-16$ & & & 7.00 & $3-15$ & & $<0.001$ \\
\hline Egocentrism & & & 10.00 & $4-18$ & & & 9.00 & $3-15$ & & 0.379 \\
\hline Frostiness & & & 11.00 & $4-15$ & & & 11.00 & $3-17$ & & 0.340 \\
\hline
\end{tabular}

SD: Standard deviation, $t$ : $t$ test value, med.: median value

OCD: Obsessive-Compulsive Disorder, YRAl: Young-Rygh Avoidance Inventory, YCl: Young Compensation Inventory

people's desires and needs at the expense of their own (24). In the OCD patients, the self-sacrifice schema scores may have been increased due to an inflated sense of responsibility.

Schema avoidance responses involve avoiding persons or situations that may trigger a person's schemas. Overcompensation responses represent attempts at "doing the opposite" of the schemas (12). As coping strategies to avoid the mentioned schemas, OCD patients showed somatization and distractionthrough-activity schemas. Furthermore, as schema overcompensation, coping reactions using status seeking, control, and intolerance for criticism schemas.

In the OCD patients, there was an increase in depression and anxiety levels. A positive correlation was found between severity of OCD and the levels of depression and anxiety. We can say that with the severity of OCD, the degree of anxiety and depression may increase, and equally, with increasing depression and anxiety levels, the severity of OCD can rise.
Treatment of anxiety and depression symptoms is thus important for the treatment of the illness itself.

We found that after adjustment for depression and anxiety levels, all schema domains (impaired autonomy, disconnection/rejection, unrelenting standards, impaired limits, and self-directedness) and the schemas failure, insufficient self-control and/or self-discipline, and selfsacrifice were predictors for the illness in OCD patients. In addition, an increase in the scores for the vulnerabilityto-harm-or-illness schema and the distraction-throughactivity schema avoidance was found to predict a decrease in the severity of the disease. Impaired autonomy involves schemas related to the neglect of basic universal needs such as autonomy and competition. The schema domain disconnection/rejection includes schemas related to the neglect of basic universal needs such as reliability, safety, stability, care, empathy, sharing of emotions, acceptance, and respect. The schema domain unrelenting standards contains schemas related with internalized rigid rules about self-assertion and ethical behavior, generally at the 
Table 5: Predictivity of early maladaptive schema scores in OCD patients for the severity of OCD

\begin{tabular}{|c|c|c|c|c|c|c|}
\hline & B & $(S D)^{a}$ & B & $(S D)^{b}$ & $\mathbf{p}^{\mathbf{a}}$ & $\mathbf{p}^{\mathbf{b}}$ \\
\hline \multicolumn{7}{|l|}{ YSQ-S3 } \\
\hline Impaired autonomy & 0.095 & 0.037 & 0.011 & 0.003 & 0.013 & 0.001 \\
\hline Enmeshment/undeveloped self & 0.136 & 0.138 & 0.041 & 0.034 & 0.329 & 0.234 \\
\hline Abandonment & -0.153 & 0.205 & -0.080 & 0.058 & 0.458 & 0.176 \\
\hline Failure & 0.310 & 0.197 & 0.120 & 0.055 & 0.123 & 0.035 \\
\hline Pessimism & 0.395 & 0.192 & 0.073 & 0.051 & 0.046 & 0.160 \\
\hline Vulnerability to harm or illness & -0.385 & 0.237 & -0.153 & 0.054 & 0.110 & 0.007 \\
\hline Disconnection/rejection & 0.139 & 0.043 & 0.017 & 0.004 & 0.002 & $<0.001$ \\
\hline Emotional deprivation & 0.253 & 0.154 & 0.030 & 0.030 & 0.108 & 0.317 \\
\hline Emotional inhibition & 0.138 & 0.207 & 0.004 & 0.043 & 0.507 & 0.930 \\
\hline Social isolation/alienation & 0.210 & 0.170 & 0.078 & 0.041 & 0.223 & 0.064 \\
\hline Defectiveness/shame & -0.039 & 0.182 & -0.061 & 0.034 & 0.833 & 0.082 \\
\hline Unrelenting standards & 0.072 & 0.116 & 0.046 & 0.010 & 0.536 & $<0.001$ \\
\hline Unrelenting standards & 0.547 & 0.229 & 0.011 & 0.062 & 0.021 & 0.856 \\
\hline Approval seeking & -0.245 & 0.174 & 0.069 & 0.041 & 0.164 & 0.100 \\
\hline Impaired limits & -0.081 & 0.154 & 0.043 & 0.012 & 0.602 & 0.001 \\
\hline Insufficient self-control and/or self-discipline & -0.081 & 0.154 & 0.043 & 0.012 & 0.602 & 0.001 \\
\hline Other-directedness & 0.099 & 0.103 & 0.026 & 0.007 & 0.344 & $<0.001$ \\
\hline Self-sacrifice & 0.232 & 0.178 & 0.096 & 0.036 & 0.198 & 0.011 \\
\hline Punitiveness & 0.029 & 0.171 & -0.024 & 0.027 & 0.865 & 0.374 \\
\hline \multicolumn{7}{|l|}{ YRAI } \\
\hline Psychosomatic symptoms & 0.453 & 0.120 & 0.080 & 0.046 & $<0.001$ & 0.090 \\
\hline $\begin{array}{l}\text { Intentionally not thinking about } \\
\text { upsetting things }\end{array}$ & -0.010 & 0.187 & 0.094 & 0.054 & 0.959 & 0.088 \\
\hline Emotion contro & -0.638 & 0.231 & -0.064 & 0.077 & 0.008 & 0.412 \\
\hline Withdrawal from people & 0.335 & 0.269 & 0.073 & 0.069 & 0.219 & 0.294 \\
\hline Distraction through activity & -0.442 & 0.308 & -0.211 & 0.086 & 0.158 & 0.018 \\
\hline Suppression of emotions & 0.175 & 0.393 & 0.132 & 0.101 & 0.657 & 0.196 \\
\hline \multicolumn{7}{|l|}{ YCI } \\
\hline Status seeking & 0.236 & 0.113 & 0.015 & 0.039 & 0.042 & 0.696 \\
\hline Control & 0.076 & 0.175 & -0.061 & 0.046 & 0.665 & 0.195 \\
\hline Rebellion & 0.594 & 0.216 & -0.038 & 0.074 & 0.009 & 0.613 \\
\hline Counterdependency & 0.081 & 0.201 & 0.107 & 0.063 & 0.687 & 0.095 \\
\hline Manipulation & -0.051 & 0.268 & 0.033 & 0.092 & 0.850 & 0.724 \\
\hline Intolerance to criticism & 0.295 & 0.397 & 0.004 & 0.133 & 0.462 & 0.974 \\
\hline Egocentrism & -1.139 & 0.434 & -0.187 & 0.161 & 0.012 & 0.252 \\
\hline Frostiness & 0.479 & 0.332 & 0.210 & 0.106 & 0.156 & 0.055 \\
\hline
\end{tabular}

a: Linear regression analysis

b: Linear regression analysis after adjusting BDI and HAM-A scores

SD: Standard deviation B: Linear regression analysis coefficient

BDI: Beck Depression Inventory, HAM-A: Hamilton Rating Scale for Anxiety, Y-BOCS: Yale- Brown Obsessive Compulsive Scale, YSQ-S3: Young Schema Questionnaire

- Short Form 3, YRAl: Young-Rygh Avoidance Inventory, YCl: Young Compensation Inventory 
expense of happiness, relaxation, self-expression, close relationships, and health. The domain impaired limits contains schemas related to deficits in responsibility towards others, internal limits, or focusing on long-term goals. The domain other-directedness includes schemas related to deficits in meeting the need for self-directedness, which is one of the basic universal needs (24). In the treatment of OCD patients, working with the schemas failure, insufficient self-control and/or self-discipline, and self-sacrifice as well as all of the disease-predicting schema domains can help reducing the severity of the illness. While the study unexpectedly found that an increase in the vulnerability-to-harm-or-illness schema score predicted a reduction in the severity of the disease in OCD patients, this may be an effect of patients using the schema avoidance by distraction through activity thinking less about their obsessions in the course of their activity.

Before adjusting depression and anxiety scores, it looked as if the schemas pessimism and unrelenting standards, schema avoidance through psychosomatic symptoms, and schema overcompensations status seeking and defiance predicted the severity of OCD. After adjusting depression and anxiety levels, it turns out that these schemas do not predict the severity of the disease but are rather correlated with anxiety and depression scores.

Given that our sample contained more university students, it may not be representative for OCD patients in the general population. Even though psychiatric comorbidities were excluded from the study, our results found unexpectedly high depression and anxiety scores among the patients. Thus we need to take into account a confounding effect of depression and anxiety symptoms when evaluating the data.

In the clinical approach to OCD patients, considering significant/common schemas and schema coping responses as expressed above and working with these schemas will be useful in the therapy and improvement of OCD patients. To determine schemas in OCD patients, broader studies in society as a whole are needed.

\begin{tabular}{|c|c|c|}
\hline \multicolumn{2}{|c|}{ Contribution Categories } & \multirow{2}{*}{\begin{tabular}{|l} 
Author Initials \\
F.K., C.C.
\end{tabular}} \\
\hline \multirow{3}{*}{ Category 1} & Concept/Design & \\
\hline & Data acquisition & F.K., C.C. \\
\hline & Data analysis/Interpretation & F.K., C.C. \\
\hline \multirow{2}{*}{ Category 2} & Drafting manuscript & F.K., C.C. \\
\hline & Critical revision of manuscript & F.K., C.C. \\
\hline Category 3 & Final approval and accountability & F.K., C.C. \\
\hline \multirow{2}{*}{ Other } & Technical or material support & N/A \\
\hline & Supervision & N/A \\
\hline
\end{tabular}

Ethics Committee Approval: The study was approved by the Local Ethics Committee.

Informed Consent: Written informed consent was obtained from the patient for the publication of the case report and the accompanying images.

Peer-review: Externally peer-reviewed.

Conflict of Interest: No conflict of interest.

Financial Disclosure: The authors declare no financial support.

\section{REFERENCES}

1. Steketee GS. Treatment of obsessive-compulsive disorder, New York: Guilford Press, 1993.

2. Young JE, Klosko JS, Weishaar ME. Schema Therapy: A Practitioner's Guide. Soylu TV (Translation Editor) Second ed., Istanbul: Litera Publishers, 2009, 101-138. (Turkish) [CrossRef]

3. Haaland AT, Vogel PA, Launes G, Haaland VO, Hansen B, Solem S, Himle JA. The role of early maladaptive schemas in predicting exposure and response prevention outcome for obsessive-compulsive disorder. Behav Res Ther 2011; 49:781-788.

4. Wilhelm S, Berman NC, Keshaviah A, Schwartz RA, Steketee G. Mechanisms of change in cognitive therapy for obsessive compulsive disorder: role of maladaptive beliefs and schemas. Behav Res Ther 2015; 65:5-10. [CrossRef]

5. Kim JE, Lee SW, Lee SJ. Relationship between early maladaptive schemas and symptom dimensions in patients with obsessivecompulsive disorder. Psychiatry Res 2014; 215:134-140. [CrossRef]

6. Kwak KH, Lee SJ. A comparative study of early maladaptive schemas in obsessive-compulsive disorder and panic disorder. Psychiatry Res 2015; 230:757-762. [CrossRef]

7. American Psychiatric Association. Diagnostic and Statistical Manual of Mental Disorders. Koroglu E (Translation Editor) Fifth ed. (DSM-5).Ankara: Physicians' Publication Association, 2013. (Turkish)

8. Goodman WK, Price LH, Rasmussen SA, Mazure C, Fleischmann RL, Hill CL, Heninger GR, Charney DS. The Yale-Brown Obsessive Compulsive Scale. I. Development, use, and reliability. Arch Gen Psychiatry 1989; 46:1006-1011. [CrossRef]

9. Karamustafalioglu KO, Ucisik AM, Ulusoy M, Erkmen H. Yale Brown Validity and reliability study for the Yale-Brown Obsessive-Compulsive Scale. National Psychiatry Congress, Proceedings Book. Bursa: Savas Offset, 1993, 86.

10. Tek C, Ulug B, Rezaki BG, Tanriverdi N, Mercan S, Demir B, Vargel S. Yale-Brown Obsessive Compulsive Scale and US National Institute of Mental Health Global Obsessive Compulsive Scale in Turkish: reliability and validity. Acta Psychiatr Scand 1995; 91:410-413. [CrossRef]

11. Young JE, Brown G. Young Schema Questionnaire. New York: Cognitive Therapy Center of New York, 1990.

12. Soygut G, Karaosmanoglu A, Cakir Z. Assessment of early maladaptive schemas: a psychometric study of the Turkish young schema questionnaire-short form-3. Turk Psikiyatri Derg $2009 ; 20: 75-84$. 
13. Young JE, Rygh J. Young-Rygh Avoidance Inventory. New York: Cognitive Therapy Center of New York, 1994.

14. Cakir Z. The Relationships Between Early Maladaptive Schemas, Perceived Parenting Styles and Schema Driven Coping Styles in Antisocial Personality Disorder: An Investigation through the Schema Therapy Model. Postgraduate Thesis, Hacettepe University, Institute for Social Sciences, Department for Psychology, Unit for Clinical Psychology. Ankara, 2007. (Turkish)

15. Young JE. Young Compensation Inventory. New York: Cognitive Therapy Center of New York, 1995.

16. Karaosmanoglu HA, Soygut G, Kabul A. Psychometric properties of the Turkish Young Compensation Inventory. Clin Psychol Psychother 2013; 20:171-179. [CrossRef]

17. Beck AT, Rush AJ, Shaw BF, Emery G. Cognitive Therapy of Depression. New York: Guilford, 1979.

18. Hisli N. A study on the validity of Beck Depression Inventory. Turkish Journal of Psychology 1988; 6:118-122. (Turkish)

19. Hisli N. Validity and reliability of the Beck Depression Inventory for university students. Turkish Journal of Psychology 1989; 7:313. (Turkish)

20. Hamilton M. The assessment of anxiety states by rating. Br J Med Psychol 1959; 32:50-55. [CrossRef]

21. Yazici MK, Demir B, Tanriverdi N, Karaagaoglu E, Yolac P. Hamilton anxiety rating scale: interrater reliabilty and validity study. Turk Psikiyatri Derg 1998; 9:114-117. (Turkish)

22. Delattre V, Servant D, Rusinek S, Lorette C, Parquet PJ, Goudemand M, Hauteketee M. The early maladaptive schemas: a study in adult patients with anxiety disorders. Encephale 2004; 30:255-258. (French) [CrossRef]

23. Atalay H, Atalay F, Karahan D, Caliskan M. Early maladaptive schemas activated in patients with obsessive compulsive disorder: a cross-sectional study. Int J Psychiatry Clin Pract 2008; 12:268279. [CrossRef]

24. Rafaeli E, Bernstein DP, Young J. Schema Therapy: Distinctive Features. Sasioglu M (Translator), Karaosmanoglu HA, Azizlerli N (Translation Editor) Istanbul: Psikonet Publications, 2016. (Turkish) 